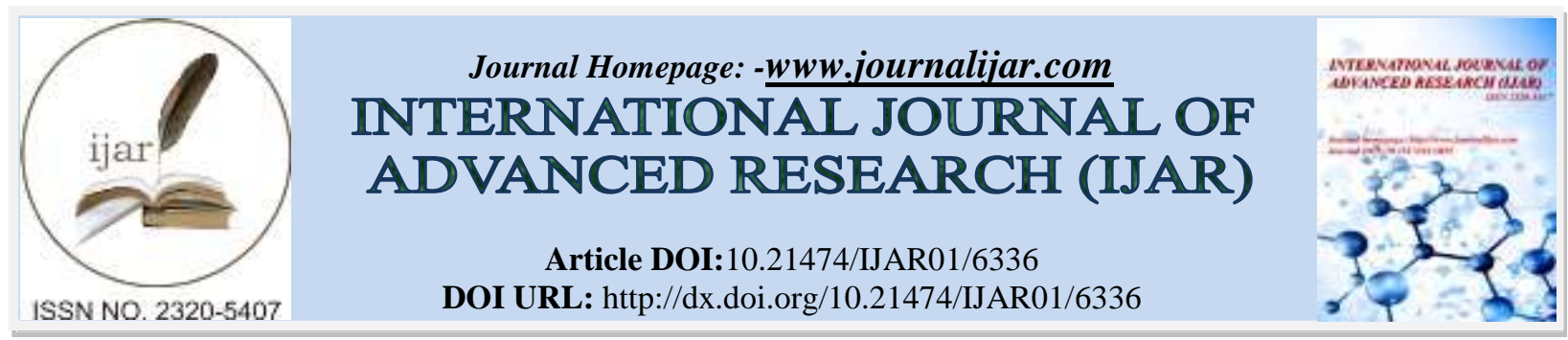

RESEARCH ARTICLE

\title{
COMPUTED TOMOGRAPHY FINDINGS IN THE SPLEEN OF SICKLE CELL PATIENTS IN SAUDI ARABIA.
}

\author{
Qasem Alalwan $^{1,3}$, Mohammed Alhaddad ${ }^{2,3}$, Mousa Alhaddad ${ }^{2,3}$, Ahmed Alsuliman ${ }^{4}$, Ali Alhawaj2, \\ Mohammed Alhajji ${ }^{2}$, Hassan Alnasser ${ }^{2}$, Yousef Alabdullah ${ }^{2}$, Ali Alabdullah ${ }^{2}$, Mohammed Alalwan $^{5}$ and \\ Malak alalwan ${ }^{6}$ \\ 1. Consultant Radiologist, King Fahad Hospital Hofuf, Saudia Arabia. \\ 2. Medical Intern, Imam Abdulrahman bin Faisal University, Saudi Arabia. \\ 3. These authors contributed equally to this work as the co-first authors. \\ 4. Consultant Hematology/Oncology, King Fahad Hospital Hofuf, Saudia Arabia. \\ 5. Medical Student, King Faisal University, Saudi Arabia. \\ 6. Medical Student,King Saud Univercity,Saudia Arabia.
}

\section{Manuscript Info}

Manuscript History

Received: 18 November 2017

Final Accepted: 20 December 2017

Published: January 2018

Key words:-

Abdominal Radiology, Computed

Tomography, Sickle Cell Disease, Spleen.

\section{Abstract}

Background: Spleen is commonly involved in sickle cell disease (SCD), and splenic abnormalities are expected to be seen in computed tomography $(\mathrm{CT})$ of nearly all patients with the disease.

Objective: The aim of this study was to evaluate the prevalence and characteristics of abnormal splenic findings in the CT-scans of SCD patients.

Materials and methods: We reviewed the medical and radiological reports of SCD patients who visited the radiology department at King Fahad Hospital -Hofuf from 2011 to 2016 for an abdominal CT scan. A consultant radiologist validated CT studies.

Results: This study included 119 patients. The mean age \pm SD was $28.67 \pm 13.57$ years. $79 \%$ of patients were adults. $10.9 \%$ of patients had a normal-sized spleen with no statistical difference among age groups. Splenomegaly was detected in $46.8 \%$ and $68 \%$ of adults and pediatrics respectively. The most common splenic pathologies were splenic infarction, fibrosis/calcification and sequestration and represented $33.6 \%, 18.5 \%$, and $4.2 \%$ of the patients. Splenic sequestrations were evident solely in the adult age group.

Conclusion:Sickle-cell related splenic complications are common. Documented splenic complications of SCD in the Eastern Province patients are similar to what has been reported internationally. Periodic radiological evaluation of the spleen as part of SCD management protocol to detect these complications is recommended.

Copy Right, IJAR, 2018,. All rights reserved.

\section{Introduction:-}

Sickle cell disease (SCD) is relatively a common genetic disorder in the Kingdom of Saudi Arabia (KSA). The Saudi Premarital Screening Program estimated the prevalence of the sickle cell gene in the adult population at $4.2 \%$ for sickle-cell trait and $0.26 \%$ for $\mathrm{SCD}$, with the highest prevalence noted in the Eastern province (approximately 
$17 \%$ for sickle-cell trait and 1.2\% for SCD). (AlHamdan et al., 2007) It was described also the Eastern Province patients are of a different clinical phenotype from the patients in the western regions of KSA. Eastern patients have more alpha thalassemia, higher total hemoglobin and fetal hemoglobin levels, and increased risk of late persistent splenomegaly (50\%) and requirement of splenectomy (20\%). (Jastaniah, 2011)

Spleen is a common organ to be involved in the complications of sickle cell disease, and splenic abnormalities are expected to be seen in computed tomography (CT) of virtually all the patients of the disease. In these patients, spleen may vary in its size from being small autosplenectomy to splenomegaly. The findings may include fibrosis, calcification, infarction, rapture, hemorrhage and sequestration. (Magid et al., 1984; Magid et al., 1987) Thus, the aim of this study was to evaluate the prevalence of the abnormal splenic findings in the CT-scans of SCD patients.

\section{Methods:-}

This study is a retrospective analysis of SCD patients. We reviewed the medical and radiological reports of SCD patients who attended the radiology department at King Fahad Hospital -Hofuf, a governmental tertiary hospital in eastern Saudi Arabia, from 2011 to 2016 for an abdominal CT scan.Three sets of data were obtained for each patient: 1- demographics(age, gender and nationality), 2- clinical presentation (abdominal pain, fever, splenic symptoms, indication for imaging etc.) and 3-radiological findings (timing of study,contrastuse,spleensize,presence of filling defects on contrast studies or low-density areas on non-contrast studies,numbers and location of these defects or areas,presence of fibrosis or calcification, and the radiologist diagnosis). After reviewing the reports, a consultant radiologist re-evaluated the $\mathrm{CT}$ studies to validate the obtained information.

The CT-scans were performed on Siemens Somatom Definition AS+ scanner using $125 \mathrm{kVp}, 3.2 \mathrm{sec}, 230 \mathrm{~mA}$, and 4 or $8 \mathrm{~mm}$ slice thickness, or on a Pfizer-AS\&E 0500 scanner with scanning techniques of $120 \mathrm{kVp}, 10 \mathrm{sec}, 20 \mathrm{~mA}$, and $10 \mathrm{~mm}$ collimation. Patients received three oral doses of $240 \mathrm{ml}$ each of a flavored $3 \%$ solution of Hypaque at $20 \mathrm{~mm}$ intervals beginning $60 \mathrm{~mm}$ before the examination. IV contrast $1 \mathrm{ml} / \mathrm{kg}$ using Omnipaque $300 \mathrm{mg} / \mathrm{ml}$. Scans were obtained at $1 \mathrm{~cm}$ intervals from the level of the diaphragm through the liver and spleen and continued caudally at $2 \mathrm{~cm}$ intervals to the symphysis pubis, with additional scans as needed.

Obtained data were coded and entered into SPSS software version 24. Frequencies were calculated by descriptive statistics and associations were determined using Chi-squared test and T-test. A P-value of less than 0.05 was considered as significant. Ethical approval was obtained from the ethical research committee of King Fahad hospital-Hofuf. All data were confidential and were used for research purposes only.

\section{Results:-}

\section{Patients characteristics:-}

This retrospective analysis included 119 patients and the sociodemographic characteristics are shown in Table 1. The mean age \pm SDwas $28.67 \pm 13.57$ years. $79 \%$ of patients were adults (> 19 years) whilst $21 \%$ were pediatric. 62 $(52.1 \%)$ were males, and 57 (47.9\%) were females. 94 patients were Saudi, and 25 patients were non-Saudi.

\section{CT scan methodology:-}

$97.5 \%$ of patients who attended the radiology department had a conventional CT scan. The other $2.5 \%$ underwent a helical CT scan $(0.8 \%)$ and a renal CT angiogram (1.7\%). Contrast was given to 115 patients $(96.6 \%)$, and $3.4 \%$ of studies were without contrast.

\section{Spleen size:-}

$10.9 \%$ of patients had a normal-sized spleen with no statistical difference among age groups. Splenomegaly was detected in $46.8 \%$ and $68 \%$ of adults and pediatrics respectively. $14.9 \%$ of adult CTs showed auto-splenectomy, while there was none among pediatrics. Pearson's test was not significant for a correlation between spleen size and age ( $\mathrm{p}$ value of 0.532). Chi-square test yielded no significant difference in spleen size among male and females ( $\mathrm{p}$ value of 0.553), and between Saudis and non-Saudis ( $\mathrm{p}$ value of 0.461 ). Details of spleen size findings are summarized in Table 2.

\section{Filling Defects:-}

Filling defects were present in 47 patients $(39.5 \%)$. Out of those, 21 were single lesions and 24 were multiple (2 missing values). Regarding the size of the filling defect, 10 were reported to be small, 4 were medium, 8 were large 
and 18 were extensive. The details of the size of filling defects are shown in Table 3.Peripheral defects (84.6\%) were more common than central defects $(7.7 \%)$ and centroperipheral defects $(7.7 \%)$.

\section{Spleen Findings:-}

Children were more likely to have a normal spleen. $60 \%$ of pediatric patients showed a normal spleen compared to $22.3 \%$ of adults $(\mathrm{p}=0.001) .36$ out of the 119 patients had normal spleen findings $(30.3 \%)$. The most common splenic finding was splenic infarction detected in $33.6 \%$ of the patients followed by fibrosis/calcification in $18.5 \%$ of patients. It was statistically less in pediatrics compared to adults $(\mathrm{p}=0.036)$. Splenic sequestration was evident in $4.2 \%$ of patients. Other reported findings, namely abscesses, empyema, cysts, and nodules were found solely in the adult age group.

\section{Extra-splenic findings:-}

Among the other intraabdominal findings, gallstones and acute cholecystitis were the commonest, occurring in $25.2 \%$ and $24.4 \%$ of patients respectively. It was noted that Non-Saudi patients displayed a higher rate of gallstones than Saudi patients $(\mathrm{p}=0.003)$. Avascular necrosis of head of femur was present in $10.1 \%$ of patients.

Table 1:- Patient's Characteristics

\begin{tabular}{|l|l|l|}
\hline Characteristic & Count $(\%)$ & Pediatrics 25(21\%) \\
\hline Age group & Adults 94(97\%) & Females 57(47.9\%) \\
\hline Gender & Male 62(52.1\%) & Non-Saudi 25(21\%) \\
\hline Nationality & Saudi 94(79\%) & \\
\hline
\end{tabular}

Table 2:- Splenic Size

\begin{tabular}{|l|l|l|l|l|l|l|}
\hline Spleen & Adults & $\%$ & Children & $\%$ & Total & $\%$ \\
\hline Enlarged & 44 & 46.8 & 17 & 68.0 & 61 & 51.3 \\
\hline $\begin{array}{l}\text { Auto- } \\
\text { splenectomy }\end{array}$ & 14 & 14.9 & 0 & 0.0 & 14 & 11.8 \\
\hline Splenectomy & 11 & 11.7 & 1 & 4.0 & 12 & 10.1 \\
\hline Normal & 8 & 8.5 & 5 & 20.0 & 13 & 10.9 \\
\hline Small & 7 & 7.4 & 0 & 0.0 & 7 & 5.9 \\
\hline Missing & 10 & 10.6 & 2 & 8.0 & 12 & 10.1 \\
\hline Total & 94 & 100 & 25 & 100 & 119 & 100 \\
\hline
\end{tabular}

Table 3:- Size of Defects

\begin{tabular}{|l|l|l|l|l|l|l|}
\hline Defects' Size & Adult & $\%$ & Children & $\%$ & Total & $\%$ \\
\hline Small & 9 & 23.7 & 1 & 11.1 & 10 & 21.3 \\
\hline Medium & 2 & 5.3 & 2 & 22.2 & 4 & 8.5 \\
\hline Large & 7 & 18.4 & 1 & 11.1 & 8 & 17.0 \\
\hline Extensive & 15 & 39.5 & 3 & 33.3 & 18 & 38.3 \\
\hline Missing & 5 & 13.2 & 2 & 22.2 & 7 & 14.9 \\
\hline Total & 38 & 100 & 9 & 100 & 47 & 100 \\
\hline
\end{tabular}

TABLE 4:- PATHOLOGICAL FINDINGS

\begin{tabular}{|l|l|l|l|l|l|l|}
\hline $\begin{array}{l}\text { Pathological } \\
\text { Findings* }\end{array}$ & Adults (94) & $\%$ & $\begin{array}{l}\text { Children } \\
(25)\end{array}$ & $\%$ & Total (119) & $\%$ \\
\hline Normal & 21 & 22.3 & 15 & 60.0 & 36 & 30.3 \\
\hline Infarction & 31 & 33.0 & 9 & 36 & 40 & 33.6 \\
\hline $\begin{array}{l}\text { Fibrosis } \\
\text { /calcification }\end{array}$ & 21 & 22.3 & 1 & 4.0 & 22 & 18.5 \\
\hline Sequestration & 5 & 5.3 & 0 & 0 & 5 & 4.2 \\
\hline Abscess & 2 & 2.1 & 0 & 0 & 2 & 1.7 \\
\hline Empyema lauto & 1 & 1.1 & 0 & 0 & 1 & 0.8 \\
\hline $\begin{array}{l}\text { Splenectomy } \\
\text { splenectomy }\end{array}$ & 26.6 & 1 & 4 & 26 & 21.8 \\
\hline
\end{tabular}




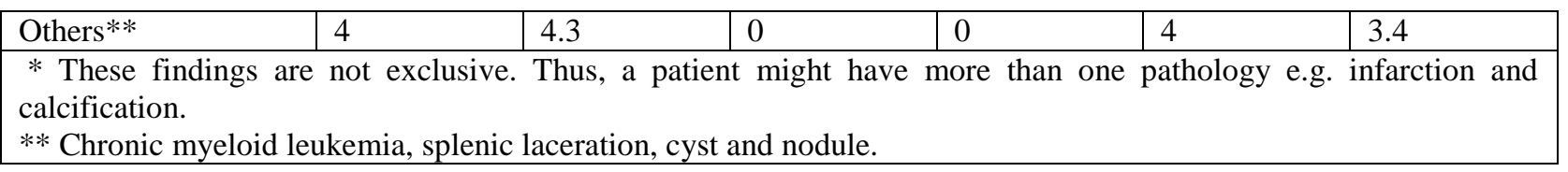

\section{Discussion:-}

SCD patients are susceptible to have different complications of the spleen. The risk of HbS polymerizing in erythrocytes increases in hypoxia, acidosis and intracellular dehydration. These altered red cell properties promote vaso-occlusive events in microcirculation, causing severe pain and end-organ ischemia, infarction and progressive dysfunction. In $\mathrm{SCD}, \mathrm{Hb}$ is particularly prone to polymerization in splenic microcirculation, and the resulting obstruction of normal blood flow may result in hypoxia and infarction of splenic tissue. Reports from the Eastern Province of Saudi Arabia and gulf region showed that spleen function is usually preserved in patients with sickle cell anemia (SCA) who presented with levels of $\mathrm{Hb} \mathrm{F}$ higher than $20 \%$ and had a high prevalence of alpha thalassemia trait. (Alsultan et al., 2013; Ngo et al., 2013; Wali et al., 2002)

This study was conducted to see the abnormal splenic finding among patients with sickle cell disease in Al-Ahsa, aregion in the Eastern Province of Saudi Arabia. The study documented different splenic pathologies that were found among 119 patients. Splenomegaly was found more in children (68\%) than in adult patients (46.8\%) with variation in size from mild to extensive enlargement. $46.8 \%$ of SCD subjects studied in this work had their spleen persisting into adult ages which is similar to what was reported in a different study in Middle Eastern SS populations. Outside Middle East (African) spleen usually undergoes auto-splenectomy by childhood period. Persistent splenomegaly in the Eastern Province SS patients can be explained may be the concomitant inheritance of alpha thalassemia or other genetic factors affecting the phenotype of the disease in the Eastern Province.

The spleen is susceptible to repeated episodes of focal veno-occlusive disease with infarction resulting in gradual perivascular fibrosis and shrinkage of the organ (auto-splenectomy) in adult life.In this present study autosplenectomy was detected in $14.9 \%$ of adult SCD patients. This trend is similar to the finding of other studies.Alternatively, splenectomy was performed in adult, and pediatric $(11.7 \%$ and $4.0 \%$ respectively) which is lower than what was reported by others. (Kattamis et al., 2003)

In our study, no significant relation found between age, gender and nationality and splenic size (p-values of 0.532 , 0.553, and 0.461, respectively). This result is consistent with the finding of Charles UgwokeEze study. (Eze et al., 2015) However, other researchers found significant correlation between age and spleen size. (Olatunji \& Olatunji, 2001; Al-Salem et al., 1998)

Acute splenic sequestration crisis is a potentially life-threatening complication and is known to one of the leading causes of death in children with sickle cell disease. Surprisingly in this study,the diagnosis of acute splenic sequestration in children group was not reported.

\section{Conclusion:-}

Sickle-cell related splenic complications are common. The documented splenic complications of SCD in the Eastern Province patients are similar to what is reported internationally. Periodic radiological evaluations of spleen as part of SCD management protocol to detect these complications are recommended. 


\section{References:-}

1. AlHamdan, N., AlMazrou, Y., AlSwaidi, F., \& Choudhry, A. (2007). Premarital screening for thalassemia and sickle cell disease in Saudi Arabia. Genetics In Medicine, 9(6), 372-377.

2. Jastaniah, W. (2011). Epidemiology of Sickle Cell Disease in Saudi Arabia. Annals Of Saudi Medicine, 31(3), 289-293.

3. Magid, D., Fishman, E., \&Siegelman, S. (1984). Computed tomography of the spleen and liver in sickle cell disease. American Journal Of Roentgenology, 143(2), 245-249.

4. Magid, D., Fishman, E., \&Siegelman, S. (1984). Computed tomography of the spleen and liver in sickle cell disease. American Journal Of Roentgenology, 143(2), 245-249.

5. Alsultan, A., Alabdulaali, M., Griffin, P., AlSuliman, A., Ghabbour, H., \&Sebastiani, P. et al. (2013). Sickle cell disease in Saudi Arabia: the phenotype in adults with the Arab-Indian haplotype is not benign. British Journal OfHaematology, 164(4), 597-604.

6. Ngo, D., Bae, H., Steinberg, M. H., Sebastiani, P., Solovieff, N., Baldwin, C. T., ... Alsultan, A. (2013). Fetal Hemoglobin in Sickle Cell Anemia: Genetic Studies of the Arab-Indian Haplotype. Blood Cells, Molecules \& Diseases, 51(1), 22-26.

7. Wali, Y., Al-Lamki, Z., Hussein, S., Bererhi, H., Kumar, D., Wasifuddin, S., Zachariah, M., \& Ghosh, K. (2002)

Splenic Function in Omani Children with Sickle Cell Disease: Correlation with Severity Index, Hemoglobin Phenotype, Iron Status, And A -Thalassemia Trait. Pediatric Hematology and Oncology 19(7), 491-500.

8. Eze, C. U., Offordile, G. C., Agwuna, K. K., Ocheni, S., Nwadike, I. U., \& Chukwu, B. F. (2015). Sonographic evaluation of the spleen among sickle cell disease patients in a teaching hospital in Nigeria. African Health Sciences, 15(3), 949-958.

9. Olatunji, A., \& Olatunji, P. (2001). Splenic size determination in sickle cell anaemia: an ultrasonographic study. East African Medical Journal, 78(7), 366.

10. Al-Salem, A., Al-Aithan, S., Bhamidipati, P., Al Jam'a, A., \& Al Dabbous, I. (1998). Sonographic Assessment of Spleen Size in Saudi Patients with Sickle Cell Disease. Annals of Saudi Medicine, 18(3), 217-220.

11. Kattamis, C., Papadaki, M., Kattamis, A., Papadaki, I., Menegas, D., Georgakopoulou, T., \&MavrommatiMetaxotou, A. (2003). Abdominal ultrasonographic findings in patients with sickle-cell anaemia and thalassaemia intermedia. Pediatric Radiology, 33(8), 515-521. 